\title{
Diretores de escola em Minas Gerais querem currículo unificado?
}

Paula Batista Lessa*

Beatriz de Basto Teixeira**

*Doutora em Educação pela Universidade Federal de Juiz de Fora e professora das séries iniciais do ensino fundamental da Prefeitura de Juiz de Fora

E-mail: paulalessa2000@ yahoo.com.br

**Doutora em Educação pela Universidade Federal de Juiz de Fora, professora do Programa de Pós-Graduação em Educação da mesma universidade e bolsista CNPq

E-mail: beatriz.teixeira@ufjf. edu.br
Resumo: Este artigo analisa dados da pesquisa Gestão escolar, recursos e desenvolvimento curricular: desafios para a liderança, realizada com apoio da Fundação de Amparo à Pesquisa do Estado de Minas Gerais (Fapemig) e do Centro de Políticas Públicas e Avaliação da Educação (CAEd) da Universidade Federal de Juiz de Fora (UFJF). 0 survey aplicado a 3.483 diretores das escolas da rede estadual mineira, em novembro de 2012, investigou sua opinião sobre a criação de um currículo unificado e padronizado no país e no estado. Os resultados podem ser considerados como um estímulo a novas reflexões sobre a necessidade de orientações curriculares para as redes de ensino, notadamente depois da forte crítica desenvolvida nos anos de 1990 aos parâmetros elaborados naquele período.

Palavras-chave: Gestão escolar. Currículo. Diretores de escola. Política curricular. 
INTRODUÇÃO

Este artigo analisa dados da pesquisa Gestão escolar, recursos $e$ desenvolvimento curricular: desafios para a liderança (TEIXEIRA et al., 2013), realizada com apoio da Fundação de Amparo à Pesquisa do Estado de Minas Gerais (Fapemig) e do Centro de Políticas Públicas e Avaliação da Educação (CAEd) da Universidade Federal de Juiz de Fora (UFJF) ${ }^{1}$. O survey aplicado a 3.483 diretores das escolas da rede estadual mineira, em novembro de 2012, investigou sua opinião sobre a criação de um currículo unificado e padronizado no país e no estado. Os resultados podem ser considerados como um estímulo a novas reflexões sobre a necessidade de orientações curriculares para as redes de ensino, notadamente depois da forte crítica desenvolvida nos anos de 1990 aos parâmetros elaborados naquele período.

A pesquisa aqui analisada dá continuidade a estudos desenvolvidos pelo Grupo de Pesquisa Política e Sociologia da Educação (GPPSE) da UFJF, inscrito no Conselho Nacional de Desenvolvimento Científico e Tecnológico (CNPq), que possui um conjunto de trabalhos sobre a gestão escolar, financiamento e política curricular.

Em relação aos Parâmetros Curriculares Nacionais do Ensino Fundamental (PCNEF), os estudos do Grupo demonstraram que essa política curricular move-se através do tempo e se integra a outras políticas e práticas desenvolvidas pelos professores, alcançando seu objetivo de orientar as escolhas curriculares feitas pelos sistemas de ensino e escolas. Também observamos que os professores têm utilizado os PCNEF em seu trabalho e que os cursos de formação inicial, continuada e concursos estão difundindo essas orientações (LESSA, 2012; TEIXEIRA; LESSA, 2010, 2011). Essa trajetória de pesquisa insiste no tema das orientações curriculares, especialmente porque depois das críticas vindas, em sua maior parte, do ambiente acadêmico à formulação de currículos unificados por nível e rede de ensino, é possível observar um movimento de criação de currículos por algumas redes estaduais e municipais. É o caso, por exemplo, de Minas Gerais, com os Conteúdos Básicos Comuns (CBC).

Com a pesquisa Gestão escolar, recursos e desenvolvimento curricular: desafios para a liderança (TEIXEIRA et al., 2013), o objetivo era reunir

1 Agradecemos a oportunidade de debater os resultados desta pesquisa com o Grupo de Pesquisa Gestão e Qualidade da Educação (Gesq) da Pontifícia Universidade Católica do Rio de Janeiro (PUC-RIO), coordenado pela professora doutora Cynthia Paes de Carvalho, durante estágio pós-doutoral na instituição, em fevereiro de 2014. 
informações sobre o papel que os diretores escolares assumem em face da implementação da política curricular. A pesquisa foi realizada através de um survey, aplicado durante o mês de novembro de 2012, junto às avaliações do Programa de Avaliação da Rede Pública de Educação Básica/Sistema Mineiro de Avaliação da Educação Pública (Proeb/Simave), pelo CAEd/UFJF. Atingimos um conjunto composto por 3.483 diretores de escolas da rede estadual mineira. Os resultados obtidos permitiram ampliar nosso conhecimento sobre como esses gestores concebem, implementam e organizam o currículo escolar.

Cabe um parêntese para explicar que nosso interesse pelo estudo do papel do diretor emergiu do entendimento de que pesquisar sobre o que ele faz é importante por ele ser o responsável pela condução de processos de planejamento e aquele que dirige a aplicação dos recursos financeiros enviados às escolas. Ele também pode se apresentar como o condutor do processo de planejamento curricular que resulta na construção de um projeto pedagógico mais - ou menos - adequado aos objetivos postos para o ensino.

Conhecer o papel que ele exerce e como lida com o currículo escolar pode contribuir para a compreensão de como sua atuação influencia os processos de implementação das políticas educacionais e de mudança nas escolas, além de colaborar com a consolidação de mais um elo investigativo entre as políticas educacionais dentro da ideia de que elas empreendem ciclos, constituindo também novos patamares investigativos.

Para atingir o objetivo estabelecido para este artigo, apresentamos e analisamos os dados coletados com o survey aplicado em novembro de 2012; retomamos o levantamento feito por Lessa (2012) sobre a produção acadêmica relativa às políticas curriculares, com destaque para o período a partir da década de 1990, relacionando-o com as proposições governamentais de criação de um currículo nacional; e finalizamos o trabalho trazendo algumas questões que surgem desse novo processo de pesquisa realizado com os diretores das escolas estaduais de Minas.

\section{DIRETORES E UM CURRÍCULO UNIFICADO}

A pesquisa Gestão escolar, recursos e desenvolvimento curricular: desafios para a liderança (TEIXEIRA et al., 2013) foi respondida por 3.483 diretores de escolas estaduais de Minas Gerais. Utilizamos um questionário aplicado por ocasião do exame do Proeb/Simave, pelo CAEd/UFJF. Após a revisão 
de literatura sobre os temas gestão escolar, financiamento da educação e currículo, as questões fechadas foram elaboradas pelo Grupo de Pesquisa, de maneira a permitirem conhecer as características socioeconômicas, os perfis de formação, a trajetória profissional e as opiniões dos gestores sobre o desenvolvimento curricular, o financiamento da educação nas suas escolas e a infraestrutura que elas possuem.

Antes de tratar propriamente do que é a questão neste artigo, apresentamos um perfil dos nossos entrevistados. 0 objetivo é mostrar que o perfil dos diretores de escola da rede estadual mineira, no momento da pesquisa, não varia em relação à pesquisa anteriormente aplicada aos ocupantes dessa função em Minas Gerais e também em relação aos profissionais em outros estados. 0 que desejamos com isso é chamar a atenção para o fato de que uma demanda de diretores em Minas Gerais pode ser a mesma de seus colegas que já estiveram no mesmo cargo ou em outros.

Para a composição do perfil dos diretores de escola, trazemos as frequências sobre sexo, idade, tempo de formação e de atuação na função de direção. Dos diretores que participaram da pesquisa, 2.652 são mulheres - isso representa $76,2 \%$ do conjunto pesquisado.

Tabela 1 - Sexo

\begin{tabular}{l|c|c} 
& Frequência & Percentual Válido (\%) \\
Masculino & 820 & 23,8 \\
Feminino & 2.625 & 76,2 \\
Total & 3.445 & 100,0 \\
Nulos & 38 & \\
Total & 3.483 & \\
\hline
\end{tabular}

Fonte: Teixeira et al. (2013).

A sinalização da predominância feminina no cargo de gestão pode ser representativa tanto de um processo de emancipação feminina no campo da educação - evidenciando que mulheres têm assumido não apenas os cargos de docência, mas também de chefia -, quanto um reflexo do processo de precarização e desprestígio do trabalho docente, que faz com os que os homens busquem novas e mais rentáveis alternativas de inserção no mercado de trabalho. Apesar de esta ser uma discussão que ultrapassa os limites deste trabalho, consideramos que a visão que essas gestoras têm sobre a ocupação feminina desse espaço de gestão impacta a forma como dirigem suas escolas.

Apesar de a faixa etária dos diretores ser bem variada, percebe-se que aquela que vai de 40 a 49 anos (46,6\%) concentra maior número de profissionais. Em 
seguida, vêm a faixa que compreende de 50 a 59 anos (28,6\%) e a de 30 a 39 $\operatorname{anos}(20,7 \%)$.

Tabela 2 - Faixa etária dos diretores

\begin{tabular}{l|c|c} 
& Frequência & Percentual Válido (\%) \\
\hline Entre 18 e 29 anos & 48 & 1,4 \\
Entre 30 e 39 anos & 700 & 20,7 \\
Entre 40 e 49 anos & 1.576 & 46,6 \\
Entre 50 e 59 anos & 968 & 28,6 \\
Acima de 60 anos & 87 & 2,6 \\
Total & 3.379 & 100,0 \\
Não responderam & 104 & \\
Total & 3.483 & \\
\hline
\end{tabular}

Fonte: Teixeira et al. (2013).

Os dados mostram que pessoas mais experientes têm assumido os cargos de direção nas escolas. Essa é uma tendência que vem sendo anunciada em outras pesquisas que trazem informações sobre os perfis dos gestores escolares. Em Minas, o estudo realizado por Teixeira (2003) sinalizou que 87,4\% dos 325 diretores pesquisados tinham entre 36 e 59 anos. A investigação amostral sobre o Perfil dos Diretores de Escola da Rede Pública, feita pela Fundação Victor Civita (2009), que abrangeu um universo de 400 diretores escolares de todo o país, revelou que os gestores pesquisados apresentavam uma média de idade de 46 anos e que 83\% deles possuíam entre 36 e 55 anos. Esses resultados parecem sugerir que a experiência e a trajetória profissional anterior ao exercício da função de direção têm tido peso na escolha desses dirigentes.

Os dados sobre o nível de escolaridade dos diretores indicam a predominância de uma formação em nível de especialização, opção indicada por 64,1\% deles. 0 percentual de licenciados que ocupam a direção das escolas pesquisadas também é considerável - são $27 \%$ do total.

Tabela 3 - Nível de escolaridade

\begin{tabular}{|c|c|c|}
\hline & Frequência & Percentual Válido (\%) \\
\hline $\begin{array}{l}\text { Ensino Fundamental } \\
\text { Ensino Médio } \\
\text { Ensino Superior - Licenciatura } \\
\text { Ensino Superior - Outros } \\
\text { Especialização (mínimo de } 360 \text { horas) } \\
\text { Mestrado } \\
\text { Doutorado ou posterior } \\
\text { Total } \\
\text { Não responderam } \\
\text { Total }\end{array}$ & $\begin{array}{l}2 \\
8 \\
925 \\
242 \\
2.195 \\
49 \\
4 \\
3.425 \\
58 \\
3.483\end{array}$ & $\begin{array}{l}0,1 \\
0,2 \\
27,0 \\
7,1 \\
64,1 \\
1,4 \\
0,1 \\
100,0\end{array}$ \\
\hline
\end{tabular}

Fonte: Teixeira et al. (2013). 
Ao todo, 65,6\% dos diretores afirmam possuir curso de pós-graduação, 64,1\% em nível de especialização, 1,4\% em nível de mestrado e 0,1\% em doutorado ou posterior. Na pesquisa realizada por Teixeira (2003), ainda predominava, entre os diretores mineiros, a formação em nível de graduação, indicada por $73 \%$ deles. Contudo, 65,2\% deles já afirmavam ter cursos de pós-graduação em nível de especialização.

$O$ investimento na formação dos gestores também tem sido assinalado em outras pesquisas. A investigação do CAEd/UFJF (2009) indicou que 69,9\% dos entrevistados cursaram especialização (360 horas), 10\% tinham curso de aperfeiçoamento (mínimo de 180 horas), 2,5\% mestrado e $0,16 \%$ doutorado. $\mathrm{Na}$ pesquisa da Fundação Vitor Civita (2009), 75\% dos diretores disseram possuir cursos de pós-graduação; destes, 5\% fizeram mestrado e 1\% doutorado. 0 investimento nessa formação pode estar relacionado à possibilidade de progressão funcional por titulação e às facilidades encontradas para ampliação da formação por meio de cursos de pós-graduação, principalmente os de especialização.

Quando perguntados sobre o tempo de experiência como diretor de escola, mais da metade dos diretores (58\%) respondeu possuir um tempo que vai até cinco anos. Também é significativo o número de dirigentes que tem entre seis e dez anos de experiência no cargo (19,4\%).

Tabela 4 - Tempo de experiência como diretor de escola

\begin{tabular}{l|l|l} 
& \multicolumn{1}{|l}{ Frequência } & \multicolumn{1}{l}{ Percentual Válido (\%) } \\
Menos de 1 ano & 1.002 & 29,2 \\
Entre 1 e 5 anos & 989 & 28,8 \\
Entre 6 e 10 anos & 666 & 19,4 \\
Entre 11 e 15 anos & 491 & 14,3 \\
Entre 16 e 20 anos & 139 & 4,1 \\
Mais de 21 anos & 143 & 4,2 \\
Total & 3.430 & 100,0 \\
Não responderam & 53 & \\
Total & 3.483 & \\
\hline
\end{tabular}

Fonte: Teixeira et al. (2013).

O estudo de Teixeira (2003) já constatava uma prática de renovação dos ocupantes do cargo de direção em Minas. Esse fato pode estar acontecendo pela implantação de políticas que determinam um tempo máximo para que os diretores fiquem no cargo e sejam reeleitos. Um exemplo é a Resolução no 1812/11, que estabelece, no Art. 43, parágrafo 1ํㅡ, que os servidores que 
tiverem período igual ou superior a quatro anos consecutivos no exercício do cargo de diretor, na mesma unidade de ensino, não poderão participar do próximo processo de indicação de candidatos ao cargo de diretor.

O que pretendemos com esses dados é sugerir que, mesmo com a alternância dos ocupantes no cargo, com uma formação acadêmica em nível mais elevado e com maior experiência de docência ou gestão escolar, a adesão à proposição de um currículo unificado por rede de ensino pode ser sinal de que uma política curricular seja elemento importante de apoio ao trabalho de gestão pedagógica.

Passamos agora propriamente às opiniões dos diretores nas questões relacionadas a currículo. A hipótese que impulsionou nossa análise foi a de que haveria uma visão favorável entre os diretores à existência de um currículo unificado por redes de ensino. Investigações anteriormente realizadas pelo GPPSE (TEIXEIRA et al., 2004; TEIXEIRA, 2006; RAINHO, 2005; PEREIRA, 2008; TEIXEIRA; LESSA, 2010) já haviam captado uma concordância da parte de professores com orientações curriculares por rede de ensino. Uma possibilidade de currículo unificado, que tínhamos como referência para a elaboração da pesquisa, pode ser lida em artigo de Cipriano Luckesi (2013), em que o autor afirma que um currículo no Brasil pode ter "(01) conteúdos nacionais (certamente, os universais da ciência e das diversas áreas de conhecimento), (02) conteúdos da cultura regional e (03) conteúdos da cultura local”. Ou seja, há conteúdos a que todos têm direito em nível nacional, mas também há possibilidade de adaptações às realidades estaduais e municipais, que podem compor um currículo unificado em cada rede de ensino, com respeito às especificidades e autonomia de cada unidade de ensino. A elaboração da proposta curricular de cada escola tomando como ponto de partida o currículo proposto para a respectiva rede de ensino seria o exercício mesmo da autonomia pedagógica.

Interessou-nos, portanto, com o survey dirigido a diretores, investigar se também entre eles estaria havendo a adesão à proposta de currículos unificados e alguns elementos que poderiam intervir sobre essa concordância. Quando questionamos sobre a criação de currículo unificado e padronizado no país, a maioria dos diretores, $67 \%$, se mostrou favorável a essa iniciativa. O percentual favorável é ainda maior, 83\%, quando os gestores são questionados sobre a criação de currículo unificado e padronizado no estado. 
Tabela 5 - Criação de currículo unificado e padronizado no país e no estado

\begin{tabular}{l|c|c|c|c} 
& \multicolumn{2}{|c|}{$\begin{array}{c}\text { Sobre a criação de currículo } \\
\text { unificado e padronizado no país. }\end{array}$} & $\begin{array}{l}\text { Sobre a criação de currículo unificado } \\
\text { e padronizado no estado. }\end{array}$ \\
\cline { 2 - 5 } & Frequência & $\begin{array}{l}\text { Percentual Válido } \\
(\%)\end{array}$ & Frequência & Percentual Válido (\%) \\
\hline Sou favorável & 2.215 & 67,0 & 2.737 & 83,0 \\
Não sou favorável & 1.091 & 33,0 & 560 & 17,0 \\
Total & 3.306 & 100,0 & 3.297 & 100,0 \\
Não responderam & 177 & & 186 & \\
Total & 3.483 & & 3.483 & \\
\hline
\end{tabular}

Fonte: Teixeira et al. (2013).

Diante desse alto percentual de concordância, decidimos cruzar suas opiniões sobre o currículo com alguns fatores que acreditamos interferir sobre esse julgamento. São eles: o tempo que o diretor atua como gestor escolar, o seu nível de formação e o tempo no exercício da função de direção em sua escola atual.

Ao compararmos o nível de anuência dos diretores sobre criação de currículo unificado e padronizado no país e no estado com seu tempo de atuação na direção de escolas, não observamos um decréscimo da concordância dos gestores relacionado ao aumento de seu tempo no exercício da função.

Tabela 6 - Tempo de experiência como diretor de escola x criação de currículo unificado e padronizado no país e no estado

\begin{tabular}{c|c|c|c|c} 
& $\begin{array}{l}\text { Sobre a criação de currículo } \\
\text { unificado e padronizado no país. }\end{array}$ & $\begin{array}{l}\text { Sobre a criação de currículo } \\
\text { unificado e padronizado no estado. }\end{array}$ \\
\hline $\begin{array}{c}\text { Tempo de } \\
\text { experiência como }\end{array}$ & Sou favorável & Não sou favorável & Sou favorável & Não sou favorável \\
diretor de escola & & & & \\
Menos de 1 ano & 67,1 & 32,9 & 84,0 & 16,0 \\
Entre 1 e 5 anos & 67,3 & 32,7 & 83,0 & 17,0 \\
Entre 6 e 10 anos & 67,0 & 33,0 & 83,0 & 17,0 \\
Entre 11 e 15 anos & 67,4 & 32,6 & 81,7 & 18,3 \\
Entre 16 e 20 anos & 65,4 & 34,6 & 81,5 & 18,5 \\
Mais de 21 anos & 63,4 & 36,6 & 82,8 & 17,2 \\
\hline
\end{tabular}

Fonte: Teixeira et al. (2013).

Dentre os diretores com menos de um ano de experiência no cargo, 67,1\% são favoráveis à criação de um currículo unificado no país e $84 \%$ no estado. Entre os profissionais que têm entre um e cinco anos de experiência no cargo, $67,3 \%$ concordam com a proposição de um currículo nacional e $83 \%$ com a de um currículo estadual. Entre seis e dez anos, esses números são de $67 \%$ 
e $83 \%$, respectivamente. Entre 11 e 15 anos, 67,4\% dos dirigentes optam por um currículo unificado para o país e $81,7 \%$ para o estado. Esse percentual também se mantém elevado entre os gestores que têm 16 anos ou mais de experiência na função.

Os dados da interseção entre a criação de um currículo unificado e padronizado no país e no estado e o tempo que o gestor está na direção de sua escola atual são apresentados na tabela seguinte.

Tabela 7 - Tempo na direção da sua escola atual x criação de currículo unificado e padronizado no país e no estado

\begin{tabular}{|c|c|c|c|c|}
\hline \multirow[b]{2}{*}{$\begin{array}{c}\text { Há quanto tempo } \\
\text { você é diretor nesta } \\
\text { escola? }\end{array}$} & \multicolumn{2}{|c|}{$\begin{array}{l}\text { Sobre a criação de } \\
\text { currículo unificado e } \\
\text { padronizado no país. }\end{array}$} & \multicolumn{2}{|c|}{$\begin{array}{l}\text { Sobre a criação de currículo } \\
\text { unificado e padronizado } \\
\text { no estado. }\end{array}$} \\
\hline & $\begin{array}{c}\text { Sou } \\
\text { favorável }\end{array}$ & $\begin{array}{l}\text { Não sou } \\
\text { favorável }\end{array}$ & $\begin{array}{c}\text { Sou } \\
\text { favorável }\end{array}$ & $\begin{array}{l}\text { Não sou } \\
\text { favorável }\end{array}$ \\
\hline $\begin{array}{l}\text { Menos de } 1 \text { ano } \\
\text { Entre } 1 \text { e } 5 \text { anos } \\
\text { Entre } 6 \text { e } 10 \text { anos } \\
\text { Entre } 11 \text { e } 15 \text { anos } \\
\text { Entre } 16 \text { e } 20 \text { anos } \\
\text { Há mais de } 21 \text { anos }\end{array}$ & $\begin{array}{l}66,8 \\
67,3 \\
66,4 \\
67,9 \\
64,2 \\
50,0\end{array}$ & $\begin{array}{l}33,2 \\
32,7 \\
33,6 \\
32,1 \\
35,8 \\
50,0\end{array}$ & $\begin{array}{l}84,2 \\
82,4 \\
82,2 \\
81,3 \\
89,3 \\
66,6\end{array}$ & $\begin{array}{l}15,8 \\
17,6 \\
17,8 \\
18,7 \\
10,7 \\
33,4\end{array}$ \\
\hline
\end{tabular}

Fonte: Teixeira et al. (2013).

Nota-se que, na média, a maioria dos diretores, 63,7\%, mantém-se favorável à ideia de um currículo unificado e padronizado para o país e que $81 \%$ deles apoiam a proposição de um único para o estado. Esse percentual não se altera, de forma significativa, entre as diferentes faixas de tempo que o gestor exerce a função de direção na sua escola atual. Observamos que o percentual total de concordância dos diretores com a criação de um currículo estadual é bem mais elevado. Isso pode estar relacionado à existência de um currículo estadual em Minas Gerais, os CBC, que estão consolidados desde 2005 e têm forte influência sobre os processos de avaliação no estado.

Os dados também indicam que a mudança do nível de escolaridade dos diretores não tem interferido sobre sua opinião a respeito do currículo unificado e padronizado no país e no estado. 
Tabela 8 - Nível de escolaridade mais elevado (já concluído) x criação de currículo unificado e padronizado no país e no estado

\begin{tabular}{l|c|c|c|c} 
& \multicolumn{2}{|c|}{$\begin{array}{l}\text { Sobre a criação de currículo } \\
\text { unificado e padronizado no país }\end{array}$} & $\begin{array}{l}\text { Sobre a criação de currículo } \\
\text { unificado e padronizado no estado }\end{array}$ \\
\hline $\begin{array}{l}\text { Nível de escolaridade mais } \\
\text { elevado (já concluído) }\end{array}$ & Sou favorável & Não sou favorável & Sou favorável & Não sou favorável \\
\hline $\begin{array}{l}\text { Ensino Fundamental } \\
\text { Ensino Médio }\end{array}$ & 100,0 & 0,0 & 50,0 & 50,0 \\
Ensino Superior & 100,0 & 0,0 & 100,0 & 0,0 \\
Licenciatura & 66,5 & 33,5 & 82,0 & 18,0 \\
Ensino Superior-Outros & 63,7 & 36,3 & 79,9 & 20,1 \\
Especialização (360 horas & 67,3 & 32,7 & 83,9 & 16,1 \\
ou mais) & 61,7 & 38,3 & 72,3 & 27,7 \\
Mestrado & 75,0 & 25,0 & 75,0 & 25,0 \\
Doutorado ou posterior & & & \\
\hline
\end{tabular}

Fonte: Teixeira et al. (2013).

Entre os diretores que possuem curso superior como a escolaridade mais elevada, há uma média de 65,1\% que se mostram favoráveis à proposta de criação de um currículo nacional e de $81 \%$ que apoiam um currículo estadual. Entre os pós-graduados, a média de concordância com essa proposta é de $68 \%$ e $77 \%$, respectivamente.

É possível que a nossa hipótese inicial, de que se estaria consolidando uma opinião favorável entre os diretores à existência de currículos unificados por redes de ensino, esteja certa, pelo menos no que diz respeito ao universo da nossa pesquisa. Quando comparamos a visão dos diretores sobre a criação de um currículo unificado e padronizado no país e no estado com os dados coletados sobre formação e experiência profissional, vemos que as frequências de concordância com essa proposta se alteram pouco ou não se alteram. Isso nos leva a crer que essa opinião favorável estaria se consolidando.

Uma forte razão para isso pode ser a expectativa de que um currículo unificado sirva como "uma pauta" com base na qual o diretor de escola possa concertar a proposta curricular com professores, especialmente aqueles da segunda etapa do ensino fundamental e do ensino médio, que podem, porventura, e na condição de especialistas em certa disciplina, colocarem-se de forma mais arredia em relação às discussões sobre conteúdos e métodos de sua atividade docente. É uma possibilidade, cabe conferir.

Mais razões pelas quais a concordância com currículo unificado merece ser mais bem analisada e investigada estão em manifestações recentes de 
autoridades educacionais. Segundo informou o secretário de Educação Básica, Romeu Caputo, em audiência na Câmara dos Deputados, o Ministério da Educação (MEC) trabalha na elaboração de uma base nacional comum para o conteúdo ensinado nas escolas brasileiras ${ }^{2}$. Além disso, em entrevista para o jornal Folha de S.Paulo, o novo presidente do Instituto Nacional de Estudos e Pesquisas Educacionais Anísio Teixeira (Inep), professor Francisco Soares, admite que o tema é polêmico, mas afirma a necessidade da definição de um currículo para a educação básica³. Nas suas próprias palavras, diz:

\begin{abstract}
Sou favorável por uma questão de justiça escolar. Temos desigualdades educacionais muito marcantes, e uma coisa absolutamente fundamental para que todos aprendam aquilo que necessitam para a cidadania é que [o currículo] esteja bem definido. [...] Não posso deixar que a definição do que é necessário para aprender seja feita pelas diferentes pessoas nos diferentes lugares. Alguns vão tomar excelentes definições. Outros, infelizmente, vão tomar definições que vão prejudicar turmas inteiras.

Aqui a gente toca num ponto muito delicado: precisamos muito do professor, mas ele implementa uma decisão de Estado. Não posso dar a cada um a possibilidade de ser o intérprete do direito à educação. Por isso que a base nacional comum é importante (SOARES, 2014).
\end{abstract}

Essas declarações reacendem, na agenda política do país, a discussão sobre a possibilidade de formulação de um currículo nacional comum. Os dados de nossa pesquisa mostram que pode ser uma demanda também daqueles que lideram o processo educativo nas escolas. Isso está na contramão das discussões sobre currículo, especialmente no meio acadêmico, nos últimos 20 anos.

\title{
CURRÍCULO UNIFICADO: TEMA POLÊMICO DA DÉCADA DE 1990 PARA CÁ
}

Uma forte relação pode ser estabelecida entre projetos de crescimento econômico e desenvolvimento, as políticas educacionais e, dentre estas, as políticas curriculares ${ }^{4}$. A década de 1990 não foi, em certo sentido, exceção. Mudanças significativas aconteciam na relação do Estado com a sociedade 2 Disponivel em: 〈http://www2.camara.leg.br/camaranoticias/noticias/EDUCACAOE-CULTURA/445479-MEC-VAI-ELABORAR-BASE-COMUM-PARA-CURRICULOS-DASESCOLAS-DO-PAIS.html>. Acesso em: 15 out. 2013.

3 Disponivel em: 〈http://www1.folha.uol.com.br/fsp/poder/156765-curriculo-do-ensinobasico-precisa-ser-mais-definido.shtmlı. Acesso em: 19 mar. 2014.

4 Entre os principais movimentos de reforma da educação da década de 1950 até hoje, um aspecto central é o currículo (ver BROOKE, 2012). Também no Brasil podemos observar como a educação é evocada como elemento de mudança toda vez que os ideais de modernização e desenvolvimento mobilizam o debate e a ação públicos (ver TEIXEIRA, 2002). 
e isso se refletia diretamente sobre as políticas públicas formuladas e implementadas no período ${ }^{5}$. Por um lado, não havia a crença no Estado como agente "competente" na promoção dessas políticas, pelo menos não como se organizava naquele momento. 0 discurso governamental da época era o de que a estabilidade do país já estava garantida, fazendo-se necessário retomar as rédeas da proposta de crescimento e desenvolvimento econômico. Crescimento dependente da modernização da administração governamental que se daria pela redução de custos e maximização dos resultados. Por outro lado, havia demandas da sociedade que clamavam por urgente atendimento, dentre elas a educação, que inclusive se colocava como condição para o crescimento e o desenvolvimento esperados e necessários.

$\mathrm{Na}$ perspectiva de crescimento, a indicação internacional de reforma do Estado e de suas instituições obtém grande repercussão no Brasil e passa a ser vista como promotora da melhoria do seu funcionamento. A redução de custos, a eficiência, a eficácia e a efetividade são apontadas como critérios para avaliação de sua ação ${ }^{6}$.

O Brasil almejava ampliar sua inserção no mercado internacional. Para isso, precisava obter melhores índices de qualidade social, de infraestrutura e desempenho econômico para aumentar o investimento de empresas estrangeiras no país e projetar os produtos brasileiros no mercado mundial. Especificamente em relação à educação, passamos, novamente, a obter financiamentos e a desenvolver projetos elaborados, coordenados e implementados pelo Fundo Monetário Internacional (FMI) e pelo Banco Mundial 7 , visando a alcançar a melhoria da qualidade de ensino, muitas vezes representada pela melhoria dos índices educacionais.

O governo brasileiro, buscando atender às exigências de reforma do sistema educacional que facilitariam o desenvolvimento do país perante o mercado internacional, valeu-se dos diagnósticos que atestavam a crise da educação para apresentariniciativas de investimento governamental na educação. Dentre elas, a de elaboração de uma orientação curricular que viesse a ser referência para o trabalho do professor, para a elaboração da proposta educativa da escola e para a realização de avaliações nacionais. A crise impunha como desafio a promoção de uma mudança paradigmática interna, de tal modo que se pudesse superar o modelo tradicional de escolarização, substituindo-o por

\footnotetext{
Ver relatório do Ipea (2007).

Ver trabalho de Costa (2000).

Ver trabalhos de Oliveira (2001) e Santos (2002).
} 
um modelo baseado nas propostas de educação permanente ${ }^{8}$.

O cenário delineado para as políticas educacionais, a partir da década de 1990, foi diferente do desejado pelos educadores que participaram dos movimentos em prol da democratização do ensino na década de $1980^{9}$. A reforma da educação, ancorada na nova Lei de Diretrizes e Bases da Educação Nacional e no Fundo de Manutenção e Desenvolvimento do Ensino Fundamental e de Valorização do Magistério (Fundef), buscou também a elaboração de orientações curriculares para todos os níveis de ensino (da educação infantil aos vários cursos de graduação em nível superior).

Entretanto, é preciso considerar que o projeto de reforma da educação não foi implementado de maneira uniforme, nem conseguiu promover uma mudança paradigmática no modelo de escolarização. Criaram-se, nos vários universos de circulação desse projeto, diferentes propostas de "superação da crise". Dourado (2007) chega, inclusive, a afirmar que as políticas governamentais implantadas no campo educacional na década de 1990 só levaram a uma hibridação de práticas e concepções, não tendo conseguido provocar mudanças (transformações) substantivas na prática educativa.

A proposta de formulação de um currículo nacional comum, que possibilitaria a regulação do funcionamento do sistema educacional, ganhou destaque na agenda política desse período. Apesar de não terem conseguido criá-lo, as políticas educacionais passaram a adotar um discurso de aperfeiçoamento dos instrumentos e técnicas de análise para aprimoramento da prática existente. Não havia um currículo nacional obrigatório, mas orientações que, de algum modo, acabaram por influenciar a formação de professores, os livros didáticos, os concursos públicos e os sistemas de avaliação (TEIXEIRA; LESSA, 2011).

Dessas orientações, uma que ganhou notoriedade foram os PCNEF, justificados oficialmente pela necessidade de cumprir o disposto no artigo 210 da Constituição Federal, ratificada pela LDB (1996), que determinava a fixação de "conteúdos mínimos para o ensino fundamental, de maneira a assegurar formação básica comum e respeito aos valores culturais e artísticos, nacionais e regionais". Muito provavelmente a notoriedade esteja associada ao fato de que seja o nível de ensino obrigatório, gratuito, prioritário, focalizado (especialmente depois do Fundef). Os PCNEF também são fruto de uma preocupação com a melhoria da qualidade da educação e com a articulação

Ver trabalho de Nagel (1992).

Ver trabalho de Arelaro (2000). 
de reformas curriculares que estavam sendo realizadas em vários estados e municípios brasileiros. Seu texto, não totalmente original, materializa uma apropriação de práticas que foram ressignificadas e reorganizadas e geraram as determinações presentes no documento ${ }^{10}$.

Após o processo de formulação e disseminação das orientações dos PCNEF, parece ter se difundido certo "constrangimento" acadêmico e também governamental de discussão e apresentação de propostas curriculares mais amplas. Diante desse silenciamento, vários estados brasileiros começaram a investir na formulação de suas próprias orientações curriculares. Um exemplo foi Minas Gerais, que, por meio da Resolução 666, de 7 de abril de 2005, instituiu conteúdos mínimos de implementação obrigatória, os Conteúdos Básicos Comuns (CBCs).

Apesar de os PCNEF ainda serem os referenciais curriculares oficiais para a organização dos currículos escolares, no caso do ensino fundamental, nas últimas décadas, o governo federal tem criado uma série de instrumentos e formulado novos materiais que têm estimulado discussões e reflexões sobre o currículo e a definição de uma base nacional comum, que garanta uma formação mínima para alunos e professores.

Em 2006, o Ministério publicou o documento Indagações sobre currículo (BEAUCHAMP; PAGEL; NASCIMENTO, 2006) com o objetivo principal de deflagrar, "em âmbito nacional, um processo de debate, nas escolas e nos sistemas de ensino, sobre a concepção de currículo e seu processo de elaboração".

No ano de 2010 foram definidas as Diretrizes Curriculares Nacionais Gerais para a Educação Básica (Resolução CNE/CEB nำ 4/2010), que fixaram normas obrigatórias que visam orientar o planejamento e o desenvolvimento curricular das escolas e dos sistemas de ensino. Em 2013, essas diretrizes foram atualizadas e reunidas em uma publicação do MEC intitulada Diretrizes Curriculares Nacionais para a Educação (DCN). De acordo com o texto do documento, a necessidade de atualização das DCN surgiu “da constatação de que as várias modificações - como o Ensino Fundamental de nove anos e a obrigatoriedade do ensino gratuito dos quatro aos 17 anos de idade deixaram as anteriores defasadas” (BRASIL, 2013, p. 4).

Essas iniciativas, além de apresentarem novos referenciais curriculares para a educação, reacendem a discussão sobre a possibilidade de criação de

10 Ver Brasil/MEC, 1997, v. 1, p. 13-15. 
um currículo nacional. A análise desse processo requer a consideração da multiplicidade e da complexidade do jogo de influências que estão presentes nesse contexto. 0 discurso que o embasa e tenta justificá-lo é construído a partir do embate de interesses entre educadores, representados ou não por comunidades epistêmicas ${ }^{11}$, grupos econômicos, forças políticas e governamentais que participam, de forma diferenciada, das várias etapas de sua elaboração e implementação. As relações, as práticas, os conhecimentos, as competências e as diferentes concepções de educação desses grupos são negociados na formação do discurso das políticas que se materializa na produção de um intertexto ${ }^{12}$ que continua a ser negociado em outros contextos de circulação.

A produção da política se configura de forma diversificada e precisa ser validada de maneira distinta pelos diversos grupos, dependendo da forma como são afetados. Em nossas pesquisas já observamos que a política curricular oficial tem ganhado espaço nos cursos de formação de professores e sido utilizada como referência no trabalho dos professores ${ }^{13}$. Passou a nos interessar a opinião de gestores escolares sobre um currículo unificado e como organizam a elaboração da proposta curricular de suas escolas.

Neste trabalho apresentamos e analisamos as respostas de diretores de escolas estaduais mineiras à pergunta sobre a existência de currículo unificado em nível estadual e nacional. Pensamos que o resultado dessa indagação pode alimentar um debate que ainda não está, na prática, encerrado.

\section{CONSIDERAÇÕES FINAIS}

A pesquisa cujos dados analisamos neste trabalho nos leva a crer na possibilidade de consolidação de uma opinião favorável, entre os diretores pesquisados, à adoção de currículos unificados por redes de ensino. Novas investigações são necessárias para que possamos ampliar a nossa compreensão sobre os fatores que podem intervir nessa ideia.

Antecipadamente, podemos supor que essa concordância dos diretores, possivelmente, esteja ancorada na necessidade de terem uma orientação curricular que os ajude na gestão do processo educativo. Teixeira e Malini (2012) sinalizam que pesquisas têm demonstrado que, embora as redes de

11 O termo comunidades epistêmicas é apresentado no trabalhado de Dias e López (2006).

12 Termo empregado anteriormente por Cury $(1998$, p. 76$)$ para definir o texto da LDB $n$ 은 9396/96.

${ }_{13}$ Ver Teixeira e Lessa (2011). 
ensino estejam investindo na formação de seus diretores, essa formação não tem conseguido auxiliar o gestor na resolução dos desafios cotidianos. Dentre esses desafios, encontra-se a gestão do currículo escolar. A preferência por um currículo unificado poderia ser explicada pela possibilidade de definição do que "deveria ser ensinado" nas escolas.

Outra razão pela qual essa opinião pode estar se disseminando entre os gestores mineiros é o fato de Minas Gerais já ter formulado, desde 2005, as suas próprias orientações curriculares. Como já mencionamos, a Resolução 666/05 instituiu os conteúdos mínimos de implementação obrigatória no estado. É possível que a vivência da implementação desse currículo tenha contribuído para reforçar a adesão dos diretores à proposta de criação de um currículo único para o país e para o estado.

É preciso considerar também que o governo de Minas tem incentivado, exigido e premiado os professores e as escolas pelo desempenho nas avaliações nacionais. Essas ações podem criar, no ideário dos diretores, a expectativa de que um currículo padronizado poderia atuar como um norteador na definição de "o que” e "como" ensinar, na articulação, organização e preparação dos alunos para a realização desses exames.

É possível que eles também considerem que esse currículo consentiria uma comparação justa e mais transparente dos resultados dos diferentes estados e regiões do país e a produção de diagnósticos mais precisos sobre a nossa realidade educacional.

Porfim, temos de ponderar que, de certa maneira, os diretores escolares podem estar respondendo positivamente às iniciativas do governo de formulação de documentos e de políticas que ofereçam orientações e norteamentos para o trabalho desenvolvido nas escolas. É possível que os dirigentes escolares estejam vendo os PCNEF, as Diretrizes Curriculares e o Plano Nacional de Educação como documentos que apoiam positivamente a gestão escolar.

Apesar de nossos dados oferecerem indícios de que os gestores escolares são favoráveis à criação de um currículo único e padronizado para o país e para o estado de Minas, vemos a necessidade de realizar estudos mais aprofundados que complementem, ampliem e diversifiquem nossa análise e que considerem outros elementos que podem estar influenciando essa opinião dos diretores. 


\section{Do Minas Gerais schools' headmasters want a unified curriculum?}

Abstract: This article examines data from Gestão escolar, recursos $e$ desenvolvimento curricular: desafios para a liderança, a research sponsored by Fundação de Amparo à Pesquisa do Estado de Minas Gerais (Fapemig) and Centro de Políticas Públicas e Avaliação da Educação (CAEd) from Universidade Federal de Juiz de Fora (UFJF). The survey applied to 3.483 school headmasters from the State of Minas Gerais' education network in November 2012 investigated their opinion on the creation of a unified and standardized curriculum in the country and in the State. Results may be considered an incentive for further reflection on the necessity of providing curricular guidelines for the education networks, particularly after the sharp criticism that took place in the 90 s to parameters elaborated in that period.

Keywords: School management. Curriculum. School headmasters. Curricular policy. 


\section{REFERÊNCIAS}

ANDRIOLI, A. I. As políticas educacionais no contexto do Neoliberalismo. Revista Espaço Acadêmico, Maringá: Editora da Universidade Estadual de Maringá, n. 13, jun. 2002. Disponível em: 〈http://www.espacoacademico. com.br/013 rea.htm». Acesso em: 9 jan. 2009.

ARELARO, L. R. G. Resistência e submissão. A reforma educacional na década de 1990. In: KRAWCZYK, N.; CAMPOS, M. M; HADDAD, S. (Orgs.). 0 cenário educacional latino-americano no limiar do século XXI: reformas em debate. Campinas: Autores Associados, 2000.

BEAUCHAMP, J.; PAGEL, S. D.; NASCIMENTO, A. R. do (Orgs.). Indagações sobre currículo. Brasília: Ministério da Educação, Secretaria de Educação Básica, 2006. 5 v.

BRASIL. Lei no 9.394, de 20 de dezembro de 1996. Estabelece as Diretrizes e Bases da Educação Nacional. Diário Oficial da União. Brasília, DF, 1996.

. Ministério da Educação. Conselho Nacional de Educação. Câmara de Educação Básica. Resolução no 4, de 13 de julho de 2010. Define as Diretrizes Curriculares Nacionais Gerais para a Educação Básica.

BRASIL. MEC. Parâmetros Curriculares Nacionais (1aa $a 4^{\underline{a}}$ séries). Brasília: MEC/SEF, 1997. $10 \mathrm{v}$.

- Secretária de Educação Básica. Diretoria de Currículos e Educação Integral. Diretrizes Curriculares Nacionais Gerais da Educação Básica. Brasília: MEC, SEB, Dicei, 2013.

BROOKE, Nigel (Org.). Marcos históricos na reforma da educação. Belo Horizonte: Fino Traço, 2012. 520 p. (Coleção EDVCERE, 19).

CAMARGO, A. M. M. de. Tendências nos currículos dos cursos de formação de professores para as séries iniciais. In: REUNIÃO ANUAL DA ANPED, 29., 2006, Caxambu. Arquivo de eventos. Disponível em: 〈http://ww.anped.org. br/reunioes/29ra/trabalhos/trabalho /GT08-1763--Int.pdf . Acesso em: 1ํ jan. 2008

CENTRO DE POLÍTICAS PÚBLICAS E AVALIAÇÃO DA EDUCAÇÃO (CAEd/ UFJF). Pesquisa nacional sobre gestão e liderança educacional. Relatório de pesquisa. Juiz de Fora: CAEd/UFJF, 2009. 
COSTA, L. C. da. O governo FHC e a reforma do estado brasileiro. Pesquisa \& Debate, São Paulo, v. 11, n. 1 (17), p. 49-79, 2000. Disponível em: 〈http:// www.pucsp.br/pos/ecopol/downloads/edicoes/\%2817\%29lucia_cortes. pdf〉. Acesso em: 12 jan. 2012.

CURY, C. R. J. Lei de Diretrizes e Bases e perspectivas da educação nacional. Revista Brasileira de Educação, Rio de Janeiro: Anped, n. 8, p. 72-85, maio/ ago. 1998.

DIAS, R. E.; LÓPEZ, S. B. Conhecimento, interesse e poder na produção de políticas curriculares. Currículo sem Fronteiras, v. 6, n. 2, p. 53-66, jul./dez. 2006. Disponível em: 〈http://www.curriculosemfronteiras.org/ vol6iss2articles/dias-lopez.pdf». Acesso em: 20 mar. 2012.

DOURADO, L. F. Políticas e gestão da educação básica no Brasil. Educação e Sociedade, Campinas: Cedes, v. 28, n. 100, p. 921-946, 2007.

FUNDAÇÃO VICTOR CIVITA. Perfil dos diretores de escola da rede pública. Relatório de Pesquisa, 2009. Disponível em: 〈http://revistaescola.abril.com. br/gestao-escolar/diretor_escolar.pdf $>$. Acesso em: 10 set. 2013.

IPEA. Políticas sociais acompanhamento e análise. Edição Especial Ipea, 2007. 377 p. Disponível em: 〈http://www.blogdoalon.com/ftp/BPS_13_completo. pdf〉. Acesso em: 10 jan. 2012.

LESSA, P. B. Os PCN em materiais didáticos para a formação de professores. Juiz de Fora, 2012. 236 f. Tese (Doutorado em Educação) - Programa de PósGraduação em Educação, Universidade Federal de Juiz de Fora.

LUCKESI, C. Avaliação de larga escala e currículo escolar nacional. Salvador: 2013. Disponivel em: 〈http://luckesi.blog.terra.com.br/2013/05/25/avaliacaode-larga-escala-e-curriculo-escolar-nacional〉. Acesso em: 7 fev. 2014.

MINAS GERAIS. SEE. Resolução no 666, de 7 de abril de 2005. Estabelece os Conteúdos Básicos Comuns - CBCs a serem obrigatoriamente ensinados pelas unidades de ensino estaduais que oferecem as séries finais do ensino fundamental e o ensino médio.

Resolução no 1812, de 22 de março de 2011. Estabelece critérios e condições para a indicação de candidatos ao cargo de diretor e à função de vice-diretor de escola estadual de Minas Gerais e trata de outros dispositivos correlatos. 
NAGEL, L. H. A crise da sociedade e da educação. Revista Apontamentos, UEM, n. 9, 1992.

OLIVEIRA, D. A. Política educacional nos anos de 1990: educação básica e empregabilidade. In: DOURADO, L. F.; PARO, V. H. (Orgs.). Políticas Públicas e Educação Básica. São Paulo: Xamã, 2001.

PEREIRA, M. C. O currículo nas escolas-referência de Minas Gerais: como a matemática chega a uma sala de aula. Juiz de Fora, 2008. Dissertação (Mestrado em Educação) - Programa de Pós-Graduação em Educação, Universidade Federal de Juiz de Fora.

RAINHO, R. R. Os Parâmetros Curriculares Nacionais em uma escola juizforana: um caso de implementação dessa orientação curricular. Juiz de Fora, 2005. Dissertação (Mestrado em Educação) - Programa de Pós-Graduação em Educação, Universidade Federal de Juiz de Fora.

SANTOS, L. L. de C. P. Políticas públicas para o ensino fundamental: Parâmetros Curriculares Nacionais e Sistema Nacional de Avaliação (Saeb). Educação e Sociedade, Campinas: Cedes, v. 23, n. 80, p. 346-367, set. 2002.

SOARES, Francisco. Currículo do ensino básico precisa ser mais definido. Folha de S. Paulo, 17 mar. 2014. Disponível em: 〈http://www1.folha.uol.com. br/fsp/poder/156765-curriculo-do-ensino-basico-precisa-ser-mais-definido. shtml>. Acesso em: 19 mar. 2014.

TEIXEIRA, B. B. A educação como um direito. In: SALGADO, M. U. C.; MIRANDA, G. V. (Orgs.). Veredas - Formação superior de professores: módulo 2, volume 1. 1. ed. Belo Horizonte: Secretaria de Estado da Educação de Minas Gerais, 2002, p. 141-170.

PCN do ensino fundamental: teoria e prática do currículo na rede estadual de ensino em Juiz de Fora. Relatório de Pesquisa. Universidade Federal de Juiz de Fora, 2006.

; FARIA, C. I. S. de; ARAÚJO, D. de F.; SOUZA, J. W. de. Os Parâmetros Curriculares Nacionais em escolas públicas de Juiz de Fora. Relatório de Pesquisa. Universidade Federal de Juiz de Fora, 2004.

; LESSA, P. B. Política curricular e processo educativo: o que professores mineiros fazem na prática com o texto. In: CALDERANO, $M$. da A.; PEREIRA, M. C.; MARQUES, G. F. C. (Orgs.). Campos e vertentes: formação, trabalho docente e avaliação sistêmica. 1. ed. Juiz de Fora: Editora da UFJF, 2010, p. 189-206. 
; - Política curricular e formação de professores: os PCN no Projeto Veredas em Minas Gerais. Currículo sem Fronteiras, v. 11, p. 36-53, 2011. Disponível em: 〈http://www.curriculosemfronteiras.org/vol11iss2articles/ teixeira-lessa.pdf ». Acesso em: 10 fev. 2012.

; MALINI, E. Formação de diretores: exigência à melhoria da gestão escolar. In: CONGRESSO IBERO-AMERICANO DE POLÍTICA E ADMINISTRAÇÃO DA EDUCAÇÃO, 3., 2012, Zaragoza, Espanha. Cadernos Anpae. Timbaúba, PE: Anpae - Espaço Livre, 2012, v. 15, p. 1-14.

et al. Gestão escolar, recursos e desenvolvimento curricular: desafios para a liderança. Relatório de Pesquisa. Juiz de Fora: UFJF/Fapemig/CAEd, 2013.

TEIXEIRA, L. H. et al. 0 diretor da unidade escolar frente a tendências presentes na gestão da escola pública de Minas Gerais. Relatório de pesquisa. Juiz de Fora: Nesce/UFJF, 2003.

RECEBIDO: Fevereiro de 2014.

APROVADO: Março de 2014. 